\title{
Analysis of genetic diversity and similarities between different Lycium varieties based on ISSR analysis and RAMP-PCR markers
}

\author{
XIAOYAN LIU ${ }^{1 *}$, JUN DU $^{2 *}$, MD. ASADUZZAMAN KHAN ${ }^{1}$, JINGLIANG CHENG $^{1}$, \\ $\mathrm{CHUNLI}_{\mathrm{WEI}}^{1,3}$, ZHIQIANG MEI ${ }^{1}$, HANCHUN CHEN ${ }^{4}$, TAO HE ${ }^{1,5}$ and JUNJIANG FU ${ }^{1,3,5}$ \\ ${ }^{1}$ Research Center for Preclinical Medicine, and ${ }^{2}$ Department of Chemistry, School of Basic Sciences, \\ Southwest Medical University, Luzhou, Sichuan 646000; ${ }^{3}$ State Key Laboratory of Quality Research in Chinese Medicine, \\ Macau University of Science and Technology, Macau (SAR) 999078; ${ }^{4}$ Department of Biochemistry and Molecular Biology, \\ School of Life Sciences, Central South University, Changsha, Hunan 410013; ${ }^{5}$ Judicial Authentication Center, \\ Southwest Medical University, Luzhou, Sichuan 646000, P.R. China
}

Received December 16, 2019; Accepted February 25, 2020

DOI: $10.3892 /$ wasj.2020.39

\begin{abstract}
The plant species Lycium, commonly known as box-thorn, is a genus of flowering plants of the Solanaceae family. It is commonly used in Traditional Chinese Medicine (TCM) for its fruits. As there are numerous different species Lycium, the present study, aimed to analyze the genetic diversity and similarities between some of these species. For this purpose, samples from 16 Lycium species were collected, and cluster dendrograms were created using random amplified microsatellite polymorphism (RAMP)-PCR and inter-simple sequence repeat (ISSR) markers. A total of 1,249 bands were produced, where each random amplified polymorphic DNA (RAPD) primer had 2-9 valuable bands with an average of 6 , of which $89.05 \%$ bands were polymorphic by RAMP-PCR. Genetic distances were observed among different cultivars or species, which had a similarity coefficient (SC) index of 0.37-0.98. Similar to RAMP-PCR, ISSR analysis of the Lycium DNA samples yielded an SC index of 0.36-0.98. ISSR markers produced 956 bands with average of 5.9 bands per ISSR primer, and $88.28 \%$ of the bands were polymorphic. The SC index between sample 2 and sample 16 was found to be 0.72 by both RAMP-PCR and ISSR, which clustered together, which indicated that these two cultivars have good genetic association, in spite of their
\end{abstract}

Correspondence to: Dr Junjiang Fu or Dr Tao He, Research Center for Preclinical Medicine, Southwest Medical University, 3-319, Zhongshan Road, Luzhou, Sichuan 646000, P.R. China

E-mail: fujunjiang@swmu.edu.cn

E-mail: hetao198@swmu.edu.cn

${ }^{*}$ Contributed equally

Key words: Lycium species, genetic authentication, RAMP-PCR, ISSR, genetic distance, genetic diversity vast geographic distance. On the whole, the present study performed a genetic analysis of different Lycium species, which may prove to be useful for the conservation of the genetic diversity of different Lycium species/cultivars, as well as of other plant species.

\section{Introduction}

Lycium is a species of plant commonly known as box-thorn, and is a genus of flowering plants of the Solanaceae family. There are numerous species of Lycium, such as Lycium barbarum, Lycium chinense, Lycium europeaum [also known as Gouji (pinyin: gǒuq̌i), or Goji (1). Carl Linnaeus, a naturalist, provided the genus name Lycium in the year 1753, and gave the species name barbarum, while Philip Miller, a botanist, described Lycium chinense after 15 years (2). The Lycium fruit, known as 'Gou qi zi', 'Gojizi', 'Wolfberry', or 'Goji berry', is the red berry obtained from two closely related species, Lycium chinense Miller and Lycium barbarum L. of the box-thorn in the family, Solanaceae, originating from Northwestern China, mainly in Ningxia, Qinghai, Gansu and Inner Mongolia (3-5). The Lycium plant is extensively cultivated in most parts of China, particularly in the Ningxia Hui Autonomous Region; however, it is also cultivated in many other parts of China and worldwide $(1,5,6)$. Lycium barbarum is regarded as Ningxia Goji, and its products have a number of medicinal properties; thus, they are a main part of Traditional Chinese Medicine (TCM).

The root bark (Digupi) and the fruit (Goji) of the Lycium plant have long been used in TCM. This therapeutic approach including Goji was first promoted by Jingyue Zhang, indicated in his book 'Jingyue Quanshu' (1640 A.D.); he advised using gentle heating and using 'thick' tonic herbs for nurturing the internal organs. During the Ming Dynasty (1368-1644 A.D.), the book 'Bencao Gangmu', written by Shizhen Li reported that the regular consumption of Goji berries generates vital energy, strengthens one's physique and increases longevity. It is well known that the Goji berry has valuable properties 
in nourishing the blood, enriching the 'Yin' (opposite to the 'Yang' in TCM), and is beneficial to the kidneys, liver and lungs (4-6). It is used in the treatment of consumptive diseases that are associated with symptoms, such as thirst, dizziness, hypoplasia and chronic cough. Furthermore, recent pharmaceutical investigations have focused on proteoglycans, such as 'Lycium barbarum polysaccharide (LBP)', which has antioxidant properties and may be effective against age-related diseases $(3,7)$. Currently, based on folk remedies and research studies, Goji berry or LBP is most well-known for the treatment of poor vision $(1,8)$, anemia (3), diabetes mellitus, memory enhancement and liver disease (6,8-11), as well as Alzheimer's disease (12), atherosclerosis (13) and other diseases (14-17). The juice products of Goji, known as Himalayan Goji Juice, are popular in the new food markets in developed countries, such as the USA and UK. In first decade of the 21st century, UK, USA, Canada and some other countries began cultivating Goji commercially to meet potential markets for fresh fruits, juice and other products (2-6).

Random amplified polymorphic DNA (RAPD), as one of the important molecular marker techniques, was first reported in 1990 by Williams et al (18). Subsequently, RAPD, alone or in combination with other molecular marker techniques, for example, inter-simple sequence repeat (ISSR), simple sequence repeat (SSR) or variable number tandem repeat (VNTR), oligonucleotide polymorphism (OP), sequence-characterized amplified region (SCAR), single nucleotide polymorphism (SNP) and amplified fragment length polymorphism (AFLP) has been widely utilized in the analysis of genetic or molecular diversity in various organisms, germplasm characterization, genotype identification and fingerprinting, estimating distances between species or offspring, and molecular marker-assisted breeding (19-25).

Although RAPD is popular due to its numerous advantages, it also possesses some drawbacks, such as poor reproducibility and a lower production rate. By using a technique of improved RAPD-PCR or random amplified microsatellite polymorphism (RAMP)-PCR, its production and resolution can be markedly increased, and its ramp time can be prolonged from $0 \mathrm{~min}$ (as in regular PCR) to 2-3 min at annealing to the extension stage in the PCR machine (termed RAMP-PCR) $(26,27)$.

There are countless Lycium species or cultivars, and confusion arises regarding the naming system and identification process. For example, the same cultivars grown in different soils or climates may produce very dissimilar fruits. Therefore, the medicinal or/and nutritional values of Lycium fruits can be significantly variable. Zhongning County in Ningxia, China is the largest producer (approximately 20\%) of Goji berries worldwide, where Lycium barbarum plantations range between 40 and 400 hectares (100-1,000 acres). As regards the importance of Lycium species and the roles of LBP in the new food market and modern medicine, research into the genetic authentication and characterization of TCM, particularly with DNA-based molecular techniques is necessary. In the present study, varieties of their samples were collected from different localities, and they were characterized genetically by RAMP-PCR, and the results were also verified by ISSR markers. Thus, the present study may provide valuable insight into genetic information and biological diversity of these medicinal plants.

\section{Materials and methods}

Experimentals. RAPD primers $(2.5 \mu \mathrm{mol} / \mathrm{l})$ are listed in Table I and ISSR primers $(2.5 \mu \mathrm{mol} / \mathrm{l})$ are listed in Table II. Taq Mastermix (2X PCR; TianGen Biotech Co. Ltd.) and the DNA molecular weight marker, DL2000 (Takara Biotechnology Co. Ltd.) were applied for PCR amplification. Other reagents that were used were all of analytical grade and have been previously described $(26,27)$.

Plant sample collection. A total of 16 Lycium species or cultivars were collected from 6 different regions of China and the USA: One from Zhongning, Lingxia (ZN), one from Gongzhou, Jiangxi (GZ), one from Panzhihua, Sichuan (PZH), 3 from Haidong, Qinghai (HD), 9 from the Ningxia Academy of Agriculture and Forestry Sciences (YC) and the last one from Houston, TX, USA (TX) (Fig. 1 and Table III).

DNA isolation. The plant genomic DNA was isolated from fresh or dried leaves using the cetyltrimethylammonium bromide (CTAB) method as previously described (27-29). DNA quality and concentration were detected by agarose gel electrophoresis and spectrophotometry (NonoDrop 2000 spectrophotometer, Thermo Fisher Scientific Inc.) (28). DNA samples were adjusted to $10 \mathrm{ng} / \mu \mathrm{l}$ as a final concentration and used for the next step of DNA amplification.

RAMP-PCR marker amplification. In total, 15 different SBS primers were first used to evaluate polymorphic detection using RAMP-PCR marker amplification. Among these, 13 primers amplified products with valuable polymorphic bands for the following data analysis (listed in Table II). Thermal cycling of PCR $(10 \mu \mathrm{l}$ in total) was carried out with the following reaction conditions: $1 \mu \mathrm{l}$ of primers, $1 \mu \mathrm{l}$ of DNA templates for Lycium cultivars or species (10 ng in total), $5 \mu 1$ of Master Mix buffer and $3 \mu \mathrm{l}$ of double-distilled water. The PCR conditions were as follows: i) Pre-denaturation at $95^{\circ} \mathrm{C}$ for $1 \mathrm{~min}$ and $30 \mathrm{sec}$; ii) $40 \mathrm{PCR}$ cycles of $40 \mathrm{sec}$ at $94^{\circ} \mathrm{C}$, $1 \mathrm{~min}$ at $36^{\circ} \mathrm{C}, 1 \mathrm{~min}$ and $30 \mathrm{sec}$ at $72^{\circ} \mathrm{C}$; and iii) extension for $5 \mathrm{~min}$ at $72^{\circ} \mathrm{C}$. PCR amplification was performed in a thermal cycler (Applied Biosystems Veriti ${ }^{\circledR}$ 96-Well Thermal Cycler, Life Technologies; Thermo Fisher Scientific, Inc.). The ramp rate (the stage from annealing to extension) was set from $5 \%$ $\left(0.125^{\circ} \mathrm{C} / \mathrm{sec}\right)$ to $10 \%\left(0.25^{\circ} \mathrm{C} / \mathrm{sec}\right)$ or to $40 \%\left(1^{\circ} \mathrm{C} / \mathrm{sec}\right)$ or to $100 \%\left(2.5^{\circ} \mathrm{C} / \mathrm{sec}\right)$, respectively for samples using RAMP-PCR to compare the reproducibility in this study. A ramp rate set to $0.125^{\circ} \mathrm{C} / \mathrm{sec}$ (5\% ramp rate) was used to execute in triplicates for each of the 16 samples (27).

ISSR marker amplification. ISSR amplification reactions were also executed in $10 \mu \mathrm{l}$ reaction volumes containing $1 \mu \mathrm{l}$ of ISSR primers, $1 \mu \mathrm{l}$ of templates for DNA of Lycium cultivars or species, $5 \mu \mathrm{l}$ of Master Mix, and $3 \mu \mathrm{l}$ of double-distilled water. The steps of the PCR reaction were as follows: i) Denaturation at $95^{\circ} \mathrm{C}$ for $1 \mathrm{~min}$ and $30 \mathrm{sec}$; ii) 35 cycles of $40 \mathrm{sec}$ at $94^{\circ} \mathrm{C}$, $30 \mathrm{sec}$ at $50^{\circ} \mathrm{C}, 1 \mathrm{~min}$ and $30 \mathrm{sec}$ at $72^{\circ} \mathrm{C}$; and iii) final extension for $5 \mathrm{~min}$ at $72^{\circ} \mathrm{C}(24)$. The PCR reaction was performed in the aforementioned PCR machine. In total, 17 primers were used initially, among which 10 primers (listed in Table II) amplified products well with high number of polymorphic bands. 
Table I. RAPD primer sequences.

\begin{tabular}{|c|c|c|c|}
\hline Primer & 5'-3' sequence & Primer & 5'-3' sequence \\
\hline SBS-A1 & CAGGCCCTTC & SBS-A7 & GAAACGGGTG \\
\hline SBS-A11 & CAATCGCCGT & SBS-A12 & TCGGCGATAG \\
\hline SBS-A16 & ACCTGGACAC & SBS-I8 & TTTGCCCGGT \\
\hline SBS-I10 & ACAACGCGAG & SBS-I18 & TGCCCAGCCT \\
\hline SBS-Q3 & ACCTCAGCTC & SBS-Q4 & AGTGCGCTGA \\
\hline SBS-Q12 & AGTAGGGCAC & SBS-Q16 & AAGCGACCTG \\
\hline SBS-Q18 & AGGCTGGGTG & & \\
\hline
\end{tabular}

Table II. ISSR primer sequences.

\begin{tabular}{|c|c|c|c|}
\hline Primer & $5^{\prime}-3^{\prime}$ sequence & Primer & $5^{\prime}-3^{\prime}$ sequence \\
\hline UBC807 & AGAGAGAGAGAGAGAGT & UBC811 & GAGAGAGAGAGAGAGAC \\
\hline UBC825 & ACACACACACACACA CT & UBC847 & CACACACACACACACARC \\
\hline UBC851 & GTGTGTGTGTGTGTGTYG & UBC876 & GACAGACAGACAGACA \\
\hline UBC879 & СТTCACTTCACTTCA & UBC880 & GGAGAG GAG AGG AGA \\
\hline UBC885 & ACACACACACACACA CYT & UBC886 & ACACACACACACACACYA \\
\hline
\end{tabular}

$\mathrm{R}$, base A or $\mathrm{G}$; Y, base $\mathrm{C}$ or $\mathrm{T}$.

Agarose gel analysis and data analysis. The PCR-amplified products were then tested on a $1.8 \%$ agarose gel electrophoresis. Ethidium bromide (EtBr) staining was used for visualizing the gels and the images were captured on a Chemi Doc XRS system (Bio-Rad Laboratories, Inc.). Bands visualized by ethidium bromide were selected on scoring for data analysis. ' 1 ' was used to mark the presence of a clear band in the gel, and ' 0 ' was used to denote that the corresponding band was absent in other sample(s). The similarity index (SI) and similarity matrix (SM) were calculated using the SM coefficient. Based on the unweighted pair group method with arithmetic averages (UPGMA), the sequential, agglomerative, hierarchical, and nested clustering (SAHN) module was used to produce the dendrograms (30).

\section{Results}

Technical comparison between regular RAPD amplification and RAMP-PCR. To obtain more specific bands from RAMP-PCR amplification, at first, the primer SBS-I4 was used for amplification with a ramp rate (from annealing to extension) of $5,10,40$ and $100 \%\left(2.5^{\circ} \mathrm{C} / \mathrm{sec}\right)$, respectively, from the Lycium barbarum 'Ningqi-1' sample (no. 7) (listed in Table III) in a PCR thermocycler. As shown in Fig. 2, the PCR bands were quantitatively increased with ramp rates from 100 to $5 \%$. The $5 \%$ ramp rate had the most bands with stronger signals. As a negative control, without a template, no bands were visible in the 5\% ramp rate. Specifically, the band numbers were 4 by regular PCR (with $100 \%$ ramp rate), and this then increased to 7 in RAMP-PCR (with a 5\% ramp rate), and signals that had at least 2 PCR bands with the $5 \%$ ramp rate were much stronger than those with the $100 \%$ ramp rate

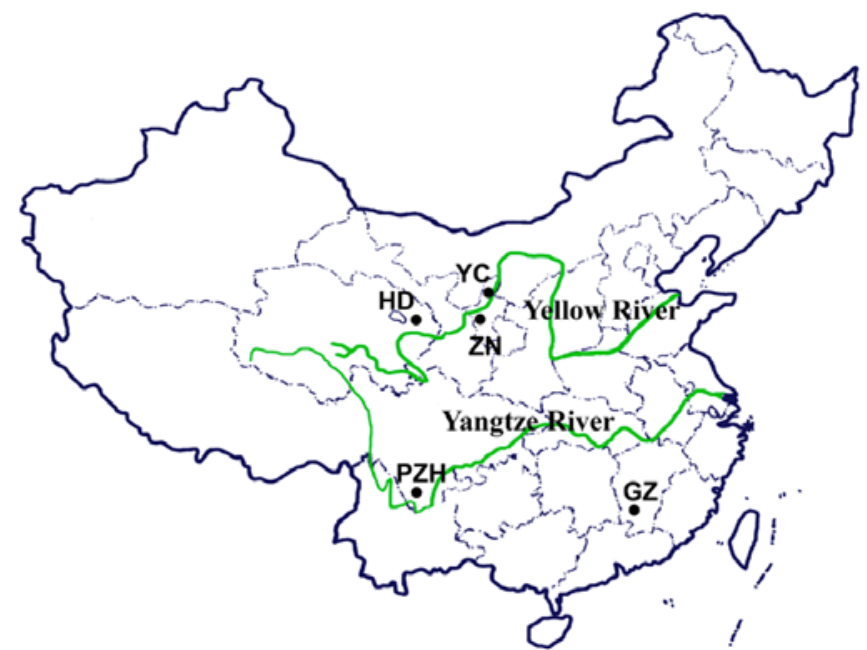

Figure 1. The localities of samples of Lycium from different regions in China. Spots in dark blue color indicate cities and lines in green color indicate Yangtze River and Yellow River, respectively. Detailed information of the 16 samples is presented in Table III.

(Fig. 2). This finding indicates that the decreased ramp rate (for example, 5\%), markedly increases the band numbers and production. Therefore, the 5\% ramp rate has better RAPD amplification, and this optimized RAMP-PCR condition was then used to complete the amplification of all 16 samples of the Lycium species or cultivars using RAPD primers.

Amplification of Lycium species or cultivars with $R A M P-P C R$. To compare whether other samples can also get more and specific bands in this study, either regular RAPD 
Table III. Lycium species sources for RAPD-ISSR analysis.

\begin{tabular}{|c|c|c|c|}
\hline No. & Species or cultivars & Sources & Abbreviation \\
\hline 1 & Lycium chinense Miller & Zhongning, Lingxia & $\mathrm{ZN}$ \\
\hline 2 & Lycium chinense Miller & Gongzhou, Jiangxi & GZ \\
\hline 3 & Lycium chinense Miller & Panzhihua, Sichuan & $\mathrm{PZH}$ \\
\hline 4 & Lycium chinense Miller (207) & Haidong, Qinghai & HD \\
\hline 5 & Lycium chinense Miller & Haidong, Qinghai & HD \\
\hline 6 & Lycium barbarum 'Ningqi-1' & Haidong, Qinghai & HD \\
\hline 7 & Lycium barbarum 'Ningqi-1' & NAAFS, Yinchuan, Lingxia & $\mathrm{YC}$ \\
\hline 8 & Lycium barbarum 'Ningqi-2' & NAAFS, Yinchuan, Lingxia & YC \\
\hline 9 & Lycium barbarum 'Ningqi-3' & NAAFS, Yinchuan, Lingxia & YC \\
\hline 10 & Lycium barbarum 'Ningqi-4' & NAAFS, Yinchuan, Lingxia & YC \\
\hline 11 & Lycium barbarum 'Ningqi-5' & NAAFS, Yinchuan, Lingxia & $\mathrm{YC}$ \\
\hline 12 & Lycium barbarum 'Ningqi-6' & NAAFS, Yinchuan, Lingxia & $\mathrm{YC}$ \\
\hline 13 & Lycium barbarum L.cv. 'Ningqi-7' & NAAFS, Yinchuan, Lingxia & $\mathrm{YC}$ \\
\hline 14 & Lycium chinense Mill. 'Cai-1' & NAAFS, Yinchuan, Lingxia & $\mathrm{YC}$ \\
\hline 15 & Lycium barbarum 'Ningqi-9' & NAAFS, Yinchuan, Lingxia & YC \\
\hline 16 & Lycium chinense Miller & Houston, TX, USA & $\mathrm{TX}$ \\
\hline
\end{tabular}

NAAFS, Ningxia Academy of Agriculture and Forestry Sciences.

or RAMP-PCR was applied to amplify the DNA samples by setting the ramp time with a ramp rate of 5 and $100 \%$ using Lycium samples (shown in Table III). The PCR product amounts and the bands numbers were obviously increased by RAMP-PCR when the ramp rate was set from 100 to 5\% (data not shown).

For the estimation of polymorphisms, 15 RAPD primers were applied for RAMP-PCR analysis and 13 of these (shown in Table I) produced polymorphic amplification bands, which were highly reproducible. In Fig. 3, 4 representative primers (SBS-A16, SBS-I1, SBS-I18 and SBS-Q12) from 16 samples are presented. From these 13 primers, a total of 1,249 bands were gained in total, where each primer exhibited 2-9 valuable bands with an average of 6 per primer. The band size was in the range of $200-2,200 \mathrm{bp}$, and $89.05 \%$ of these were polymorphic in the 16 samples.

Genetic distance analysis based on RAMP-PCR results. The cluster dendrogram based on the RAMP-PCR amplified bands is presented in Fig. 4. The dendrogram results presented a similarity coefficient (SC) index ranging from 0.37 to 0.98 . The SC index between sample 1 (Lycium chinense Miller from Zhongning, Linxia) and sample 2 (from Gongzhou, Jiangxi) was the lowest (0.37), while that between samples 6 and 7 (Lycium barbarum 'Ningqi-1' from Haidong, Qinghai and form the Ningxia Academy of Agriculture and Forestry Sciences) was the highest (0.98) (Fig. 4B). Samples 6 and 7, where were obtained from different localities, were identified with the highes SC index 0.98, indicating that they indeed originated from the same cultivar.

Amplification of Lycium species or cultivars DNAs by ISSR. In ISSR-PCR, 10 primers amplified well, which generated 956 reproducible bands from 16 samples. Each reproducible

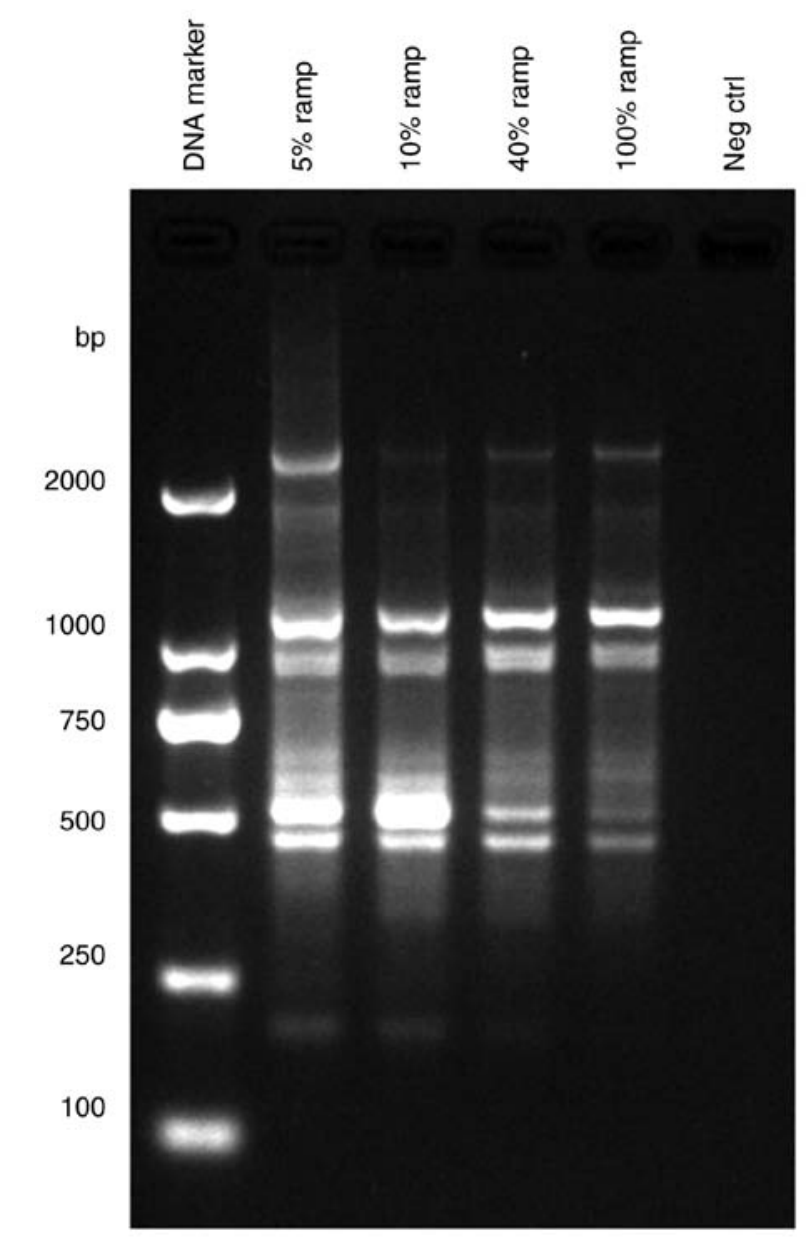

Figure 2. PCR by RAPD amplification with different ramp rates. The sample of Lycium barbarum 'Ningqi-1' sample (no. 7) from Yinchuan, Lingxia was used for RAMP-PCR using SBS-I4 primer at ramp rates of 5, 10, 40 and $100 \%$, respectively. The lane labeled 'DNA Marker' indicates the molecular weight size in bp. Neg ctrl, negative control (no template DNA). 
A

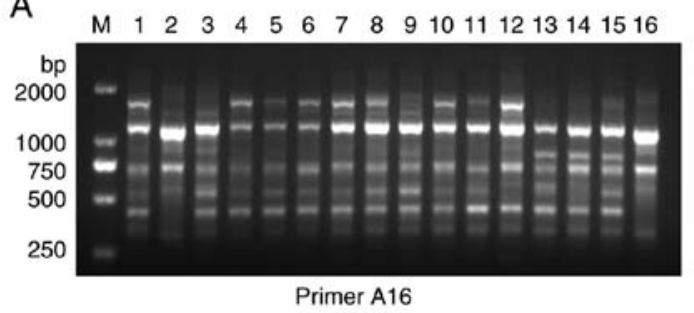

C $\quad M \quad 1 \quad 2 \quad 3 \quad 4 \quad 5 \quad 6 \quad 7 \quad 8 \quad 910111213141516$

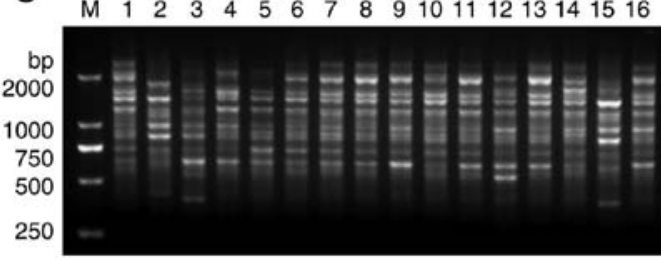

Primer 118
B

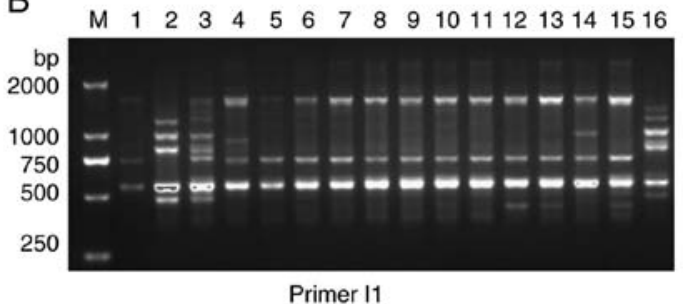

$\mathrm{D}$

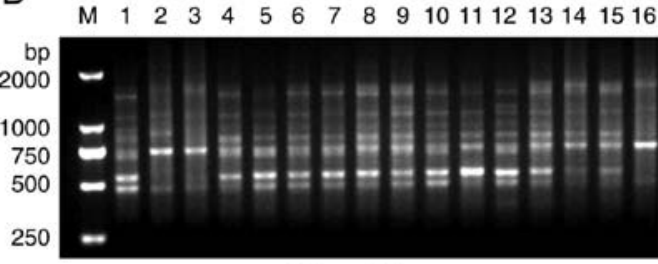

Primer Q12

Figure 3. Representative results of RAMP-PCR with a ramp rate of 5\% using RAPD primers (A) SBS-A6, (B) SBS-I1, (C) SBS-I18 and (D) SBS-Q12. Lanes 1-16 represent different Lycium samples listed in Table III, whereas lane 'M' indicates the DL2000 DNA marker.

A

B

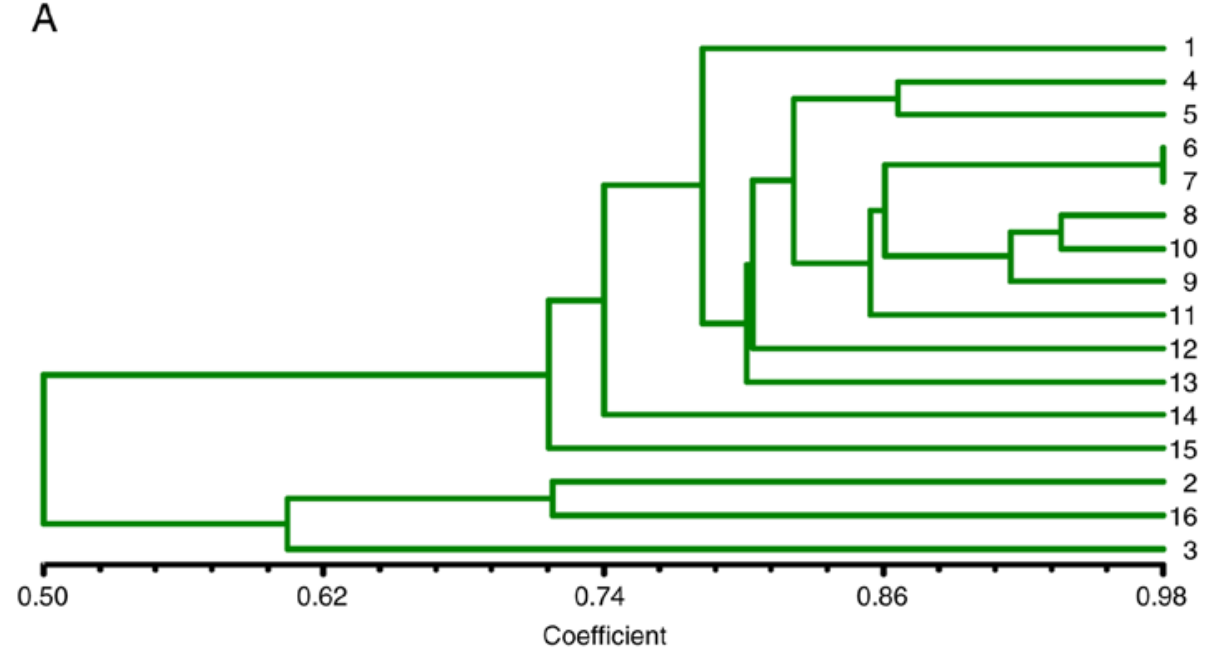

\begin{tabular}{|c|c|c|c|c|c|c|c|c|c|c|c|c|c|c|c|c|}
\hline No. & 1 & 2 & 3 & 4 & 5 & 6 & 7 & 8 & 9 & 10 & 11 & 12 & 13 & 14 & 15 & 16 \\
\hline 1 & 1.00 & & & & & & & & & & & & & & & \\
\hline 2 & 0.37 & 1.00 & & & & & & & & & & & & & & \\
\hline 3 & 0.52 & 0.66 & 1.00 & & & & & & & & & & & & & \\
\hline 4 & 0.77 & 0.47 & 0.57 & 1.00 & & & & & & & & & & & & \\
\hline 5 & 0.79 & 0.48 & 0.61 & 0.87 & 1.00 & & & & & & & & & & & \\
\hline 6 & 0.80 & 0.42 & 0.55 & 0.83 & 0.87 & 1.00 & & & & & & & & & & \\
\hline 7 & 0.80 & 0.43 & 0.57 & 0.83 & 0.87 & 0.98 & 1.00 & & & & & & & & & \\
\hline 8 & 0.80 & 0.43 & 0.57 & 0.81 & 0.85 & 0.88 & 0.90 & 1.00 & & & & & & & & \\
\hline 9 & 0.77 & 0.43 & 0.59 & 0.78 & 0.77 & 0.82 & 0.83 & 0.90 & 1.00 & & & & & & & \\
\hline 10 & 0.81 & 0.44 & 0.59 & 0.82 & 0.84 & 0.87 & 0.89 & 0.94 & 0.93 & 1.00 & & & & & & \\
\hline 11 & 0.80 & 0.42 & 0.58 & 0.79 & 0.83 & 0.84 & 0.86 & 0.86 & 0.83 & 0.89 & 1.00 & & & & & \\
\hline 12 & 0.77 & 0.46 & 0.56 & 0.78 & 0.83 & 0.80 & 0.80 & 0.83 & 0.77 & 0.81 & 0.83 & 1.00 & & & & \\
\hline 13 & 0.75 & 0.42 & 0.58 & 0.76 & 0.78 & 0.79 & 0.81 & 0.81 & 0.82 & 0.83 & 0.84 & 0.80 & 1.00 & & & \\
\hline 14 & 0.67 & 0.48 & 0.59 & 0.77 & 0.76 & 0.73 & 0.73 & 0.77 & 0.76 & 0.77 & 0.77 & 0.72 & 0.75 & 1.00 & & \\
\hline 15 & 0.63 & 0.46 & 0.56 & 0.71 & 0.72 & 0.70 & 0.70 & 0.77 & 0.76 & 0.70 & 0.73 & 0.76 & 0.73 & 0.74 & 1.00 & \\
\hline 16 & 0.48 & 0.72 & 0.56 & 0.52 & 0.53 & 0.50 & 0.49 & 0.50 & 0.50 & 0.51 & 0.47 & 0.50 & 0.50 & 0.58 & 0.46 & 1.00 \\
\hline
\end{tabular}

Figure 4. Dendrogram of Lycium varieties by the RAMP-PCR marker technique. (A) Dendrogram of Lycium varieties based on RAMP-PCR profiles. Bars on the bottom section indicate the SC index. (B) Dendrogram of genetic distance for Lycium varieties using RAMP-PCR amplification. SC, similarity coefficient. 
A

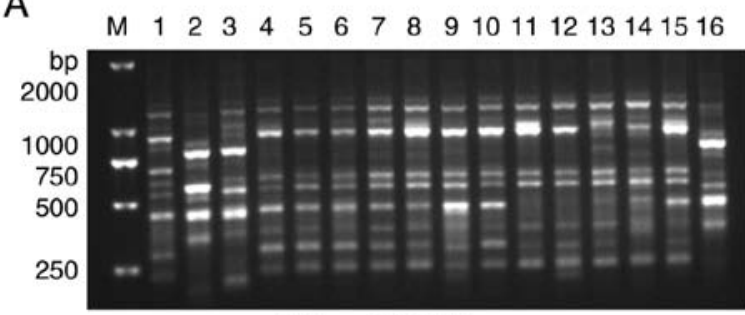

Primer UBC807

C

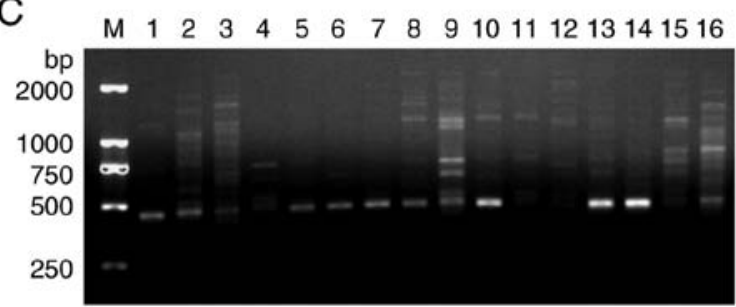

Primer UBC879
B

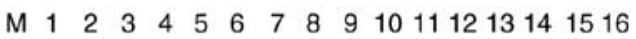

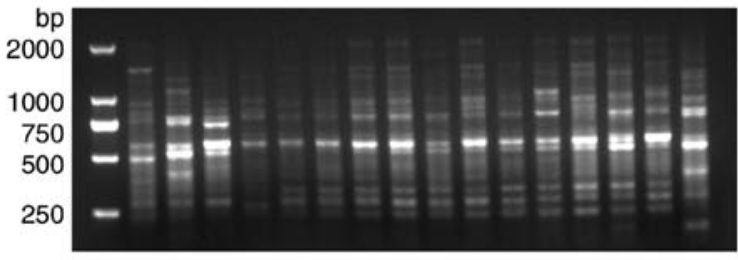

Primer UBC811

D

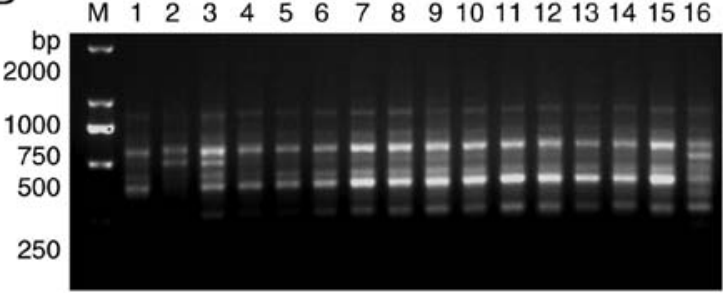

Primer UBC885

Figure 5. Representative results by ISSR makers in Lycium varieties gained by ISSR primers for (A) UBC807, (B) UBC811, (C) UBC879 and (D) UBC885. Lanes 1-16 represent different Lycium samples listed in Table III, whereas lane 'M' indicates the DL2000 DNA marker.

A

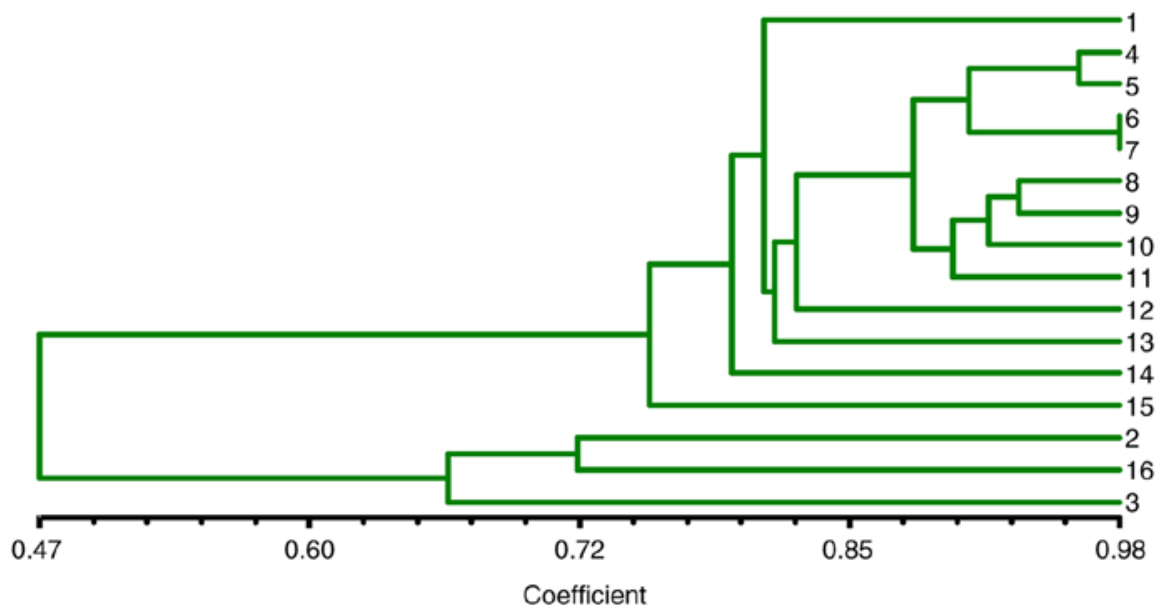

B

\begin{tabular}{|c|c|c|c|c|c|c|c|c|c|c|c|c|c|c|c|c|}
\hline No. 1 & 1 & 2 & 3 & 4 & 5 & 6 & 7 & 8 & 9 & 10 & 11 & 12 & 13 & 14 & 15 & 16 \\
\hline 1 & 1.00 & & & & & & & & & & & & & & & \\
\hline 2 & 0.36 & 1.00 & & & & & & & & & & & & & & \\
\hline 3 & 0.59 & 0.71 & 1.00 & & & & & & & & & & & & & \\
\hline 4 & 0.86 & 0.39 & 0.58 & 1.00 & & & & & & & & & & & & \\
\hline 5 & 0.86 & 0.37 & 0.58 & 0.96 & 1.00 & & & & & & & & & & & \\
\hline 6 & 0.87 & 0.36 & 0.61 & 0.90 & 0.93 & 1.00 & & & & & & & & & & \\
\hline 7 & 0.87 & 0.36 & 0.61 & 0.90 & 0.91 & 0.98 & 1.00 & & & & & & & & & \\
\hline 8 & 0.81 & 0.38 & 0.57 & 0.90 & 0.90 & 0.90 & 0.92 & 1.00 & & & & & & & & \\
\hline 9 & 0.76 & 0.41 & 0.60 & 0.85 & 0.85 & 0.86 & 0.88 & 0.93 & 1.00 & & & & & & & \\
\hline 10 & 0.82 & 0.37 & 0.58 & 0.89 & 0.89 & 0.90 & 0.91 & 0.93 & 0.90 & 1.00 & & & & & & \\
\hline 11 & 0.78 & 0.35 & 0.54 & 0.87 & 0.89 & 0.88 & 0.88 & 0.93 & 0.87 & 0.90 & 1.00 & & & & & \\
\hline 12 & 0.72 & 0.39 & 0.54 & 0.83 & 0.85 & 0.82 & 0.82 & 0.82 & 0.79 & 0.81 & 0.89 & 1.00 & & & & \\
\hline 13 & 0.78 & 0.37 & 0.58 & 0.79 & 0.81 & 0.84 & 0.84 & 0.84 & 0.77 & 0.83 & 0.85 & 0.79 & 1.00 & & & \\
\hline 14 & 0.75 & 0.42 & 0.59 & 0.82 & 0.80 & 0.81 & 0.83 & 0.81 & 0.76 & 0.84 & 0.78 & 0.78 & 0.78 & 1.00 & & \\
\hline 15 & 0.74 & 0.43 & 0.52 & 0.77 & 0.75 & 0.72 & 0.74 & 0.78 & 0.73 & 0.77 & 0.79 & 0.71 & 0.79 & 0.78 & 1.00 & \\
\hline 16 & 0.37 & 0.72 & 0.61 & 0.42 & 0.42 & 0.43 & 0.43 & 0.45 & 0.42 & 0.46 & 0.44 & 0.50 & 0.50 & 0.50 & 0.46 & 1.00 \\
\hline
\end{tabular}

Figure 6. Dendrogram of Lycium varieties of ISSR markers. (A) Dendrogram of Lycium varieties using ISSR makers. Bars on the bottom sectoin indicate the SC index. (B) Dendrogram of genetic distance for Lycium varieties using ISSR markers. SC, similarity coefficient. 
primer amplified 1-10 bands and revealed an average number of 5.9 bands per ISSR primer. The band size ranged between $200-2,000 \mathrm{bp}$, and $88.28 \%$ of the bands were revealed as polymorphic in these 16 samples. The representative results of the primers UBC807, UBC811, UBC879 and UBC885 are presented in Fig. 5. These findings provided a very clear detection of DNA polymorphisms in Lycium species or cultivars.

Results of genetic distance and cluster analysis in ISSR amplification. A cluster dendrogram was also obtained from ISSR amplification profiles. It revealed similar results to those produced by RAMP-PCR as regards the SC index among Lycium samples (Fig. 6). The dendrogram illustrated that the SC index among the samples ranged from 0.36 to 0.98 . The SC index between sample 1 and sample 2 (Lycium chinense Miller from Zhongning, Linxia and from Gongzhou, Jiangxi) was the lowest (0.36), and that between samples 6 and 7 of Lycium barbarum ('Ningqi-1' from Haidong, Qinghai and from the Ningxia Academy of Agriculture and Forestry Sciences), was the highest (0.98) (Fig. 6B), indicating that they are the same cultivar. All these data are consistent with the RAMP-PCR results and genetic analysis.

\section{Discussion}

The present study presented the first overview, to the best of our knowledge, of the genetic variability of Lycium barbarum cultivars or species, using both developed RAMP-PCR and ISSR molecular markers. Notably, the Standardization Administration of China (SAC), implemented in July 1, 2015, has approved 'Rules for agricultural seed testing-Verification of genuineness and cultivar' (GB/T3543.5-1995; https://www. codeofchina.com/standard/GBT3543.5-1995.html) as the national standard, no. 1 modification item, in which the regulation for variety authenticity or identity allows DNA molecular detection methods, including SSR and SNP molecular markers, and provides a strong basis for combating various illegal acts of counterfeit rapidly and accurately. The classic markers used by genetic ecologists are DNA sequencing which has also been required to develop SNPs, another codominant and highly polymorphic marker. Based on direct DNA sequencing, such as next generation sequencing (NGS), short tandem repeat (STR) and SNP markers can provide large genome coverage, and exhibit a high level of variability, and thus can be used for phylogenetic studies (31). STR analysis has been successfully and widely used to evaluate genotypes in humans in judicial authentication and forensic sciences (32). However, due to plant genomic complexity, the genomic information remains largely unknown; STR and SNP markers cannot be used for the genetic authentication of plants or herbs.

Given the advantages and disadvantages of different molecular genetic marker techniques, it is important to design the most effective method in order to address particular ecological questions. In RAMP-PCR, where the ramp time is prolonged at the stage from annealing to extension, the resolution and production are greatly increased compared to regular RAPD $(25,26,33)$. The present study, using RAMP-PCR and ISSR marker techniques, successfully characterized and authenticated Lycium varieties from different geographic regions indicating that samples 6 and 7 were the same cultivar.
Moreover, the similarity coefficient index between samples 2 (Lycium chinense Miller from Gongzhou, Jiangxi) and 16 (Lycium chinense Miller from Houston, TX, USA) was found to be 0.72 by RAMP-PCR and 0.72 by ISSR, which clustered together, indicating that these two cultivars have a good genetic association, although a diverse geographic distance. The results of RAMP-PCR and ISSR were both mutually consistent. RAMP is a PCR-based technique, which combines ISSR and RAPD analysis, which can generate useful molecular markers, investigate DNA polymorphisms, and can be used to elucidate the genetic associations among accessions, including Lycium varieties (34).

In conclusion, the present study combined RAMP-PCR and ISSR to analyze the genetic association and distance of Lycium varieties comprehensively. To the best of our knowledge, the present study is the first to genetically characterize the molecular diversity of Lycium varieties by combining these two methods, and this molecular characterization may prove to be useful for the conservation and preservation of DNA diversity of Lycium species.

\section{Acknowledgements}

The authors would like to thank Miss S. Fu from the University of Houston for providing critical comments and advice on the manuscript.

\section{Funding}

The present study was funded in part by the National Natural Science Foundation of China (grant no. 81672887) and the Joint Research Foundation of Luzhou City and Southwest Medical University (grant no. 2018LZXNYD-YL01).

\section{Availability of data and materials}

The data and material that support the findings of this study are available from the corresponding author upon reasonable request.

\section{Authors' contributions}

$\mathrm{XL}, \mathrm{JD}, \mathrm{CW}$ and ZM were involved in the study methodology and in performing the experiments. $\mathrm{JC}$ was involved in data analysis. JF was involved in the conception of the study, and in the writing and preparation of the original draft. $\mathrm{MK}$ and $\mathrm{JF}$ were involved in the conception of the study, and in the editing and revising of the manuscript. HC, TH and JF designed and supervised the study. All authors have read and approved the final manuscript.

\section{Ethics approval and consent to participate}

Not applicable.

\section{Patient consent for publication}

Not applicable.

\section{Competing interests}

The authors declare that they have no competing interests. 


\section{References}

1. Dong JZ, Yang JJ and Wang Y: Resources of Lycium species and related research progress. Zhongguo Zhong Yao Za Zhi 33: 2020-2027, 2008 (In Chinese).

2. Ram VJ: Herbal preparations as a source of hepatoprotective agents. Drug News Perspect 14: 353-363, 2001.

3. Potterat O: Goji (Lycium barbarum and L. chinense): Phytochemistry, pharmacology and safety in the perspective of traditional uses and recent popularity. Planta Med 76: 7-19, 2010

4. Ulbricht C, Bryan JK, Costa D, Culwell S, Giese N, Isaac R, Nummy K, Pham T, Rapp C, Rusie E, et al: An evidence-based systematic review of Goji (Lycium spp.) by the natural standard research collaboration. J Diet Suppl 12: 184-240, 2015.

5. Jin M, Huang Q, Zhao K and Shang P: Biological activities and potential health benefit effects of polysaccharides isolated from Lycium barbarum L. Int J Biol Macromol 54: 16-23, 2013.

6. Chang RC and So KF: Use of anti-aging herbal medicine, Lycium barbarum, against aging-associated diseases. What do we know so far? Cell Mol Neurobiol 28: 643-652, 2008.

7. Ma ZF, Zhang H, The SS, Wang CW, Zhang Y, Hayford F, Wang L, Ma T, Dong Z, Zhang Y and Zhu Y: Goji berries as a potential natural antioxidant medicine: An insight into their molecular mechanisms of action. Oxid Med Cell Longev 2019: 2437397, 2019.

8. Liu L, Lao W, Ji QS, Yang ZH, Yu GC and Zhong JX: Lycium barbarum polysaccharides protected human retinal pigment epithelial cells against oxidative stress-induced apoptosis. Int J Ophthalmol 8: 11-16, 2015.

9. Lam CS, Tipoe GL, So KF and Fung ML: Neuroprotective mechanism of Lycium barbarum polysaccharides against hippocampal-dependent spatial memory deficits in a rat model of obstructive sleep apnea. PLoS One 10: e0117990, 2015.

10. Yu H, Wark L, Ji H, Willard L, Jaing Y, Han J, He H, Ortiz E, Zhang Y: Medeiros DM and Lin D: Dietary wolfberry upregulates carotenoid metabolic genes and enhances mitochondrial biogenesis in the retina of $\mathrm{db} / \mathrm{db}$ diabetic mice. Mol Nutr Food Res 57: 1158-1169, 2013.

11. Lin J, Zhang Y, Wang X and Wang W: Lycium ruthenicum extract alleviates high-fat diet-induced nonalcoholic fatty liver disease via enhancing the AMPK signaling pathway. Mol Med Rep 12: 3835-3840, 2015

12. Ye M, Moon J, Yang J, Hwa Lim H, Bin Hong S, Shim I and Bae H: The standardized Lycium chinense fruit extract protects against Alzheimer's disease in 3xTg-AD mice. J Ethnopharmacol 172: 85-90, 2015

13. Lin L, Li J, Lv H, Ma Y and Qian Y: Effect of Lycium ruthenicum anthocyanins on atherosclerosis in mice. Zhongguo Zhong Yao Za Zhi 37: 1460-1466, 2012 (In Chinese).

14. Zhao R, Cai Y, Shao X and Ma B: Improving the activity of Lycium barbarum polysaccharide on sub-health mice. Food Funct 6: 2033-2040, 2015.

15. Dursun R,Zengin Y, Gündüz E, İçer M, Durgun HM, Dağgulli M, Kaplan I, Alabalık U and Güloğlu C: The protective effect of goji berry extract in ischemic reperfusion in testis torsion. Int J Clin Exp Med 8: 2727-2733, 2015.

16. Telang N, Li G, Sepkovic D, Bradlow HL and Wong GY: Comparative efficacy of extracts from Lycium barbarum bark and fruit on estrogen receptor positive human mammary carcinoma MCF-7 cells. Nutr Cancer 66: 278-284, 2014.

17. Chao JC, Chiang SW, Wang CC, Tsai YH and Wu MS: Hot water-extracted Lycium barbarum and Rehmannia glutinosa inhibit proliferation and induce apoptosis of hepatocellular carcinoma cells. World J Gastroenterol 12: 4478-4484, 2006.
18. Williams JG, Kubelik AR, Livak KJ, Rafalski JA and Tingey SV: DNA polymorphisms amplified by arbitrary primers are useful as genetic markers. Nucleic Acids Res 18: 6531-6535, 1990.

19. Hess J, Kadereit JW and Vargas P: The colonization history of Olea europaea L. In Macaronesia based on internal transcribed spacer 1 (ITS-1) sequences, randomly amplified polymorphic DNAs (RAPD), and inter simple sequence repeats (ISSR). Mol Ecol 9: 857-868, 2000.

20. Agarwal M, Shrivastava N and Padh H: Advances in molecular marker techniques and their applications in plant sciences. Plant Cell Rep 27: 617-631, 2008.

21. Varela ES, Lima JP, Galdino AS, Pinto Lda S, Bezerra WM, Nunes EP, Alves MA and Grangeiro TB: Relationships in subtribe Diocleinae (Leguminosae; Papilionoideae) inferred from internal transcribed spacer sequences from nuclear ribosomal DNA. Phytochemistry 65: 59-69, 2004.

22. Taški-Ajduković K, Nagl N, Ćurčić Z and Zorić M: Estimation of genetic diversity and relationship in sugar beet pollinators based on SSR markers. Electronic J Biotechnol 27: 1-7, 2017.

23. Pachuau L, Atom AD and Thangjam R: Genome classification of musa cultivars from northeast india as revealed by ITS and IRAP markers. Appl Biochem Biotechnol 172: 3939-3948, 2014.

24. Mei Z, Zhang X, Khan MA, Imani S, Liu X, Zou H, Wei C and Fu J: Genetic analysis of Penthorum chinense Pursh. By improved-RAPD and ISSR in China. Electron J Biotechnol 30: 6-11, 2017.

25. Fu S, Cheng J, Wei C, Yang L, Xiao X, Zhang D, Stewart MD and Fu J: Development of diagnostic SCAR markers for genomic DNA amplifications in breast carcinoma by DNA cloning of high-GC RAMP-PCR fragments. Oncotarget 8: 43866-43877, 2017.

26. Fu JJ, Li LY, Xu X, Wang Z, Tang G, Yin C and Lu G: An improved method for increasing the efficiency of the technique of random amplified polymorphic DNA (RAPD). Hereditas 22: 251-252, 1999.

27. Fu J, Yang L, Khan MA and Mei Z: Genetic characterization and authentication of Lonicera japonica Thunb. By using improved RAPD analysis. Mol Biol Rep 40: 5993-5999, 2013.

28. Fu J: Short protocols in medical molecular biology. China Medical Science Press, 2012.

29. Mei Z, Khan MA, Zhang X and Fu J: Rapid and accurate genetic authentication of Penthorum chinense by improved RAPD-derived species-specific SCAR markers. Biodiversitas 18: 1243-1249, 2017.

30. Rohlf FJ: NTSYS-pc: Numerical Taxonomy and Multivariate Analysis System, version 2.1. Exeter Publishing, Setauket, NY, 2000.

31. Robertson M and Richards C: Opportunities and challenges of next-generation sequencing applications in ecological epigenetics. Mol Ecol 24: 3799-37801, 2015.

32. Fu J, Cheng J, Liu X, Li J, Wei C, Zheng X, He T and Fu J: Evaluation genotypes of cancer cell lines HCC1954 and SiHa by short tandem repeat (STR) analysis and DNA sequencing. Mol Biol Rep 45: 2689-2695, 2018.

33. Mei Z, Zhang X, Liu X, Imani S and Fu J: Genetic analysis of Canarium album in the different areas of China by improved-RAPD and ISSR. CR Biol 340: 558-564, 2017.

34. Liang HY, Liu XJ and Yang MS: Analysis of Lycium chinense variety revealed by RAMP-PCR method. Chinese Agric Sci Bull 26: 61-64, 2011.

This work is licensed under a Creative Commons Attribution-NonCommercial-NoDerivatives 4.0 International (CC BY-NC-ND 4.0) License. 